\title{
SISTEM KEAMANAN SEPEDA MOTOR MENGGUNAKAN MIKROKONTROLLER ARDUINO UNO R3 DENGAN SENSOR HC-SR501 DAN HC-SR04
}

\author{
Harun Sujadi, Pafsi Paisal \\ Program Studi Teknik Informatika, Universitas Majalengka \\ Jln. KH. Abdul Halim. No. 103 Majalengka 45416 \\ harunsujadi@gmail.com,pafsip@gmail.com
}

\begin{abstract}
Abstrak
Pencurian sepeda motor pada saat ini semakin marak. Hal ini bisa terjadi di karenakan beberapa faktor selain kelalaian manusia yaitu masih belum adanya sistem keamanan sepeda motor yang memadai. Sistem keamanan sepeda motor keluaran pabrik hanya berupa keamanan system lock. Namun keamanan ini masih kurang efektif karena system lock tersebut dapat dilumpuhkan Banyak cara yang bisa di lakukan oleh pencuri motor untuk membongkar sistem keamanan motor yaitu dengan cara membobol kunci. Ada yang secara paksa dan yang lebih pintarnya lagi para pelaku sudah menggunakan sebuah cairan khusus untuk membobol kunci. Selain itu tindak pencurian sepeda motor kebanyakan terjadi karena kondisi lingkungan yang tidak cepat merespon atas kejadian pencurian tersebut, akibatnya sepeda motor tersebut dapat dengan leluasa dioperasikan oleh pencuri.
\end{abstract}

Berdasarkan hal tersebut, maka perlunya suatu sistem keamanan sepeda motor yang handal dan responsive. Sistem keamanan ini memanfaatkan teknologi mikrokontroller arduino dan sensor HCSR501 dan HC-SR04 serta rangkaian hardware lainnya yang dipasang pada sepeda motor. Sistem keamanan sepeda motor ini bisa dikendalikan dengan smartphone android oleh pemiliknya. Selain itu membantu pemilik sepeda motor untuk memonitoring sistem keamanan sepeda motornya yaitu dengan adanya pesan pemberitahuan pada aplikasi smartphone dan pemebritahuan SMS kepada pemilik sepeda motor ketika sepeda motornya dalam kondisi tidak aman. Diman nantinya pemilik sepeda motor bisa memilih untuk menelpon pihak berwajib atau tidak jika terjadi pencurian sepeda motor. Dengan seperti itu diharapkan bisa mengurangi angka pencurian sepeda motor.
Kata kunci:

sistem keamanan, mikrokontroller, android

\begin{abstract}
Now, crime of motorcycle theft more rife. This can happen cause some factors, besides man negligence, that is no security system yet adequate. Motorcycle security system from factory output just security lock system. But, that is not effective, because security system lock still can broken by thief. Many ways that can doit for broken security system that is dismantle key of motorcycle. Thief broken it by force or they use special chemical liquid for to broke motorcycle key. Other than that. Crime of motorcycle theft offten occur because conditions of environment not fast respond when happen motorcycle theft. Consequently, thief can freely controll that motorcycle.
\end{abstract}

Based on these, then the necessity a reliable and responsive motorcycle security system. This security system make use of microcontroller Arduino technology and sensors HC-SR501, sensors HC-SRO4, and other hardware circuit mounted on the motorcycle. This motorcycle security system can controlled with smartphone android by its owner motorcycle. Other than that can help owner motorcycle for monitor this motorcycle with notification short message and notification in application at smartphone android from owner motorcycle when motorcycle in condition not safe. Where later owner motorcycle can choose for calling authorities or no, if it happens motorcycle theft. With that, expected can reduce crime of motorcycle theft.

Keywords:

Security system, microcontroller, android 


\section{Pendahuluan}

Jumlah produksi kendaraan bermotor pada saat ini mencapai jutaan unit. Dari tahun 2012 sampai tahun 2014 jumlah produksi sepeda motor mengalami peningkatan. Pada tahun 2014 jumlah produksi sepeda motor mencapai 92.976.240 unit sepeda motor (BPS, 2016). Namun sayangnya banyaknya jumlah sepeda motor yang diproduksi oleh Indonesia saat ini belum diimbangi dengan sistem keamanan sepeda motor yang memadai. Akibatnya angka pencurian sepeda motor di Indonesia juga mengalami peningkatan.

Pada 2015, Badan Pusat Statistik (BPS) mencatat pencurian kendaraan sepeda motor terjadi tidak kurang dari 38 ribu kali di seluruh wilayah Indonesia. Tempat yang berpotensi terjadinya pencurian sepeda motor salah satunya seperti permukiman warga di Desa (BPS, 2016). Desa Panyingkiran dalam waktu 3 tahun kebelakang yaitu tahun 2014 sampai tahun 2016 angka pencurian sepeda motor mengalami peningkatan terutama pada tahun 2014 ke tahun 2015. Dari 2 kasus menjadi 3 kasus.

Selain itu dari jumlah statistik pencurian sepeda motor di Desa Panyingkiran, tidak ada satupun sepeda motor yang kembali ditemukan, ketika sepeda motor sudah dicuri oleh pelaku. Sehingga pemilik sepeda motor pun merasa khawatir dengan banyaknya terjadi kasus pencurian sepeda motor tersebut.

Berdasarkan keadaan yang demikian, perlunya sebuah solusi untuk meminimalisir tindak pencurian sepeda motor, maka penulis mencoba merancang sebuah penelitian yang berjudul "Prototipe Sistem Keamanan Sepeda Motor Menggunakan Mikrokontroller Arduino Uno R3 Dengan Sensor HCSR501 Dan HC-SR04".

\section{LANDASAN TEORI}

Berikut merupakan teori-teori yang berhubungan dengan penelitian ini.

\section{II.1 Sistem Keamanan}

Sistem keamanan adalah sistem yang digunakan untuk memberikan rasa aman dan tentram serta bebas dari bahaya ataupun ancaman, sehingga individu tidak merasa takut, resah, atau gelisah terhadap barang berharga yang ditinggalkan. sistem keamanan dapat mengetahui kemungkinan adanya tanda-tanda bahaya akan terjadinya tindak pencurian terhadap barang berharga.

\section{II.2 Pengertian Prototipe}

Proses pengembangan sistem seringkali menggunakan pendekatan prototipe (prototyping). Metode ini sangat baik digunakan untuk menyelesaikan masalah kesalahpahaman antara user dan analis yang timbul akibat user tidak mampu mendefinisikan secara jelas kebutuhannya (Mulyanto, 2009).

Berdasarkan pemaparan-pemaparan diatas, maka prototipe adalah bentuk (model) awal dari suatu sistem yang akan dibangun guna memenuhi kebutuhan user secara cepat serta mempunyai tujuan yaitu mengembangkan model awal software menjadi sebuah sistem yang final.

Sebagian user kesulitan mengungkapkan keinginannya untuk mendapatkan aplikasi yang sesuai dengan kebutuhannya. Kesulitan ini yang perlu diselesaikan oleh analis dengan memahami kebutuhan user dan menerjemahkannya ke dalam bentuk model (prototipe). Model ini selanjutnya diperbaiki secara terus menerus sampai sesuai dengan kebutuhan user.

\section{II.3 Mikrokontroler}

Mikrokontroler adalah salah satu dari bagian dasar dari suatu system komputer. Meskipun mempunyai bentuk yang jauh lebih kecil dari suatu komputer pribadi dan komputer mainframe, mikrokontroler dibangun dari elemen-elemen dasar yang sama. Secara sederhana, komputer akan menghasilkan output yang spesifik berdasarkan input yang diterima dan program yang dikerjakan. Seperti umumnya komputer, mikrokontroler sebagai alat yang mengerjakan perintah-perintah yang diberikan kepadanya. Artinya, bagian terpenting dan utama dari suatu sistem komputerisasi adalah program itu sendiri yang dibuat oleh seorang programmer. Program ini memerintahkan computer untuk melakukan jalinan yang panjang dari aksi-aksi sederhana untuk melakukan tugas yang lebih kompleks yang diinginkan oleh programmer. Sistem dengan mikrokontroler umumnya menggunakan piranti input yang jauh lebih kecil seperti saklar atau keypad kecil. Hampir semua input mikrokontroler hanya dapat memproses sinyal input digital dengan tegangan yang sama dengan tegangan logika dari sumber. Tegangan positif sumber umumnya adalah 5 volt. Padahal dalam 
dunia nyata terdapat banyak sinyal analog atau sinyal dengan tegangan level (Safaat, 2012).

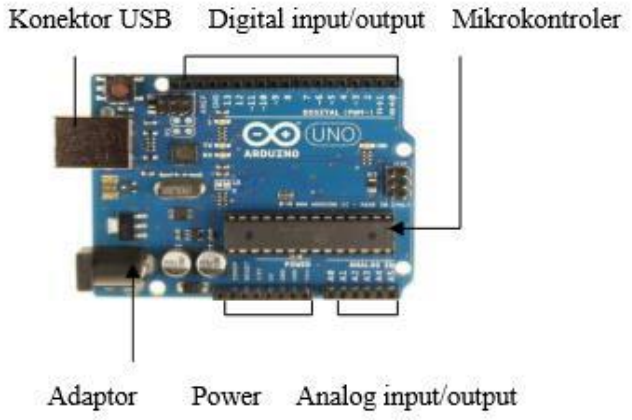

Gambar 2. Arduino Uno R3

Mikrokontroler ATMega328 TMega328 merupakan mikrokontroler keluarga AVR 8 bit. Beberapa tipe mikrokontroler yang sama dengan ATMega8 ini antara lain ATMega8535, ATMega16, ATMega32, ATmega328, yang membedakan antara mikrokontroler antara lain adalah, ukuran memori, banyaknya GPIO (pin input/output), peripherial (USART, timer, counter, dll). Dari segi ukuran fisik, ATMega328 memiliki ukuran fisik lebih kecil dibandingkan dengan beberapa mikrokontroler diatas. Namun untuk segi memori dan periperial lainnya ATMega328 tidak kalah dengan yang lainnya karena ukuran memori dan periperialnya relatif sama (Artanto, 2012)

\section{II.4 Android}

Android adalah sistem operasi berbasis Linux bagi telepon seluler seperti telepon pintar dan komputer tablet. Android juga menyediakan platform terbuka bagi para pengembang untuk menciptakan aplikasi mereka sendiri yang akan digunakan untuk berbagai macam piranti gerak. Awalnya, Google Inc. membeli Android Inc., pendatang baru yang membuat piranti lunak untuk ponsel. kemudian dalam pengembangan Android, dibentuklah Open Handset Alliance, konsorsium dari 34 perusahaan piranti keras, piranti lunak, dan telekomunikasi, termasuk Google, HTC, Intel, Motorola, Qualcomm, T-Mobile, dan Nvidia (Safaat, 2011)

\section{Analisis dan Perancangan}

Berdasarkan sistem keamanan sepeda yang berlangsung. maka sistem keamanan sepeda motor yang diusulkan adalah seperti Gambar 3 yaitu

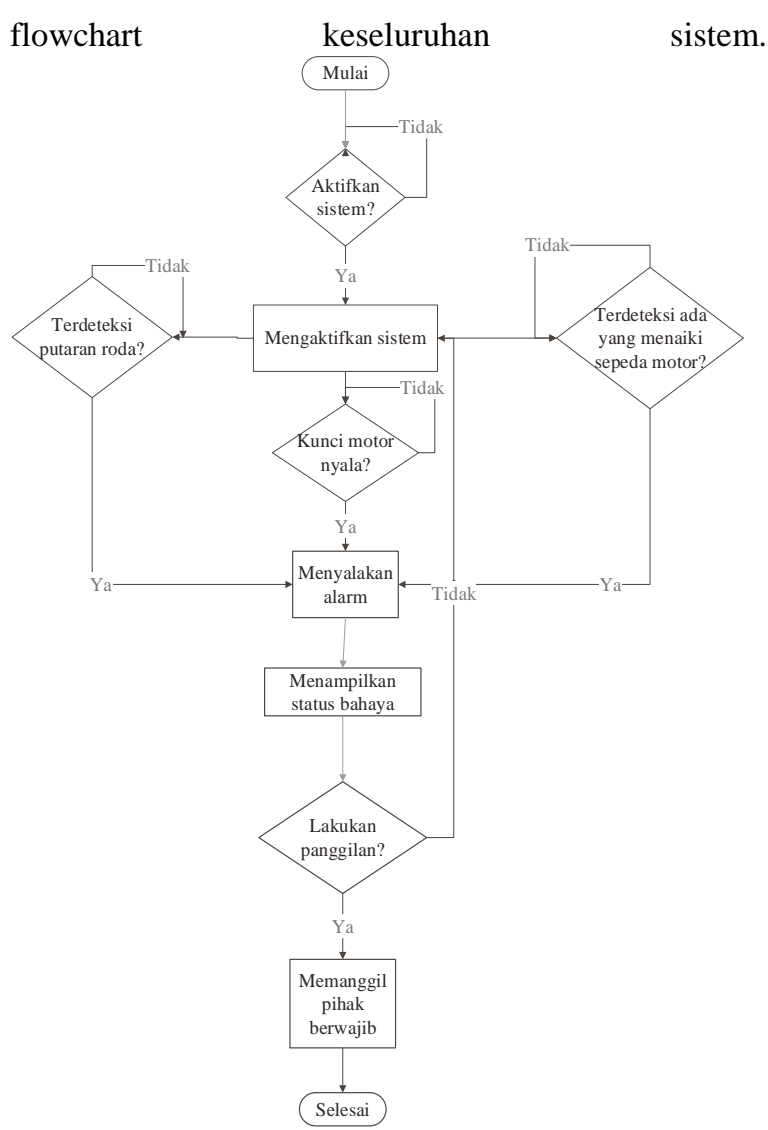

Gambar 3. Flowchart sistem keamanan sepeda motor yang diusulkan

\section{III.1 Perancangan rangkaian perangkat keras}

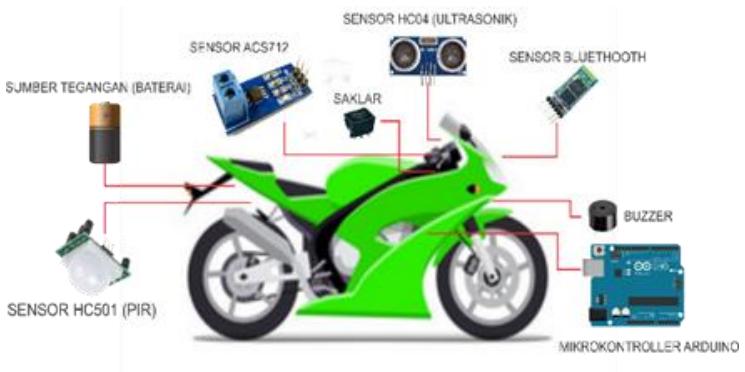

Gambar 4. Skema Prototipe Sistem usulan

Gambar 4 menunjukkan skema prototipe sistem usulan. Dalam rangkaian sistem ini berisi diagram keseluruhan sistem secara garis besar tapi tetap menjelaskan dan menggambarkan cara kerja dari sistem keamanan sepeda motor. 
Penjelasan gambar 4 adalah sebagai berikut:

1. Skema prototipe ini digunakan untuk media simulasi atau pengujian Prototipe Sistem Keamanan Sepeda Motor Menggunakan Mikrokontroller Arduino Uno R3 Dengan Sensor Hc-Sr501 Dan Hc-Sr04.

2. Pada prototipe tersebut yang termasuk perangkat keras dominan:

a. Pada prototipe ini menggunakan Arduino UNO R3 dengan mikrokontroler atmega 328 sebagai pengendali sistem dan sudah ditanamkan program yang mampu mengintegrasikan beberapa perangkat keras dan perangkat lunak.

b. Sensor HC-SR501, dipasang diatas roda beakang sepeda motor pada spakboard atas. Untuk mendeteksi putaran roda belakang sepeda motor.

c. Sensor HC-SR04, dipasang didepan dekat setir sepeda motor menghadap kearah belakang. Untuk mendeteksi adanya manusia yang menaiki sepeda motor. Tersebut.

d. Sensor ACS712, dipasang diantara sumber tegangan dan kunci kontak sepeda motor. Untuk mendeteksi tegangan jika sistem keamanan diaktifkan.

e. Bluethooth HC-06, dipasang sebagai media transmisi data antara rangkaian perangkat lunka dengan aplikasi pada smartphone pemilik sepeda motor.

f. buzzer, dipasang sebagai alarm pemberitahuan jika sepeda motor dalam kondisi tidak aman.

Pada saat sistem dihidupkan dan sensor pada keamanan sepeda motor lalu menampilkannya di di smartphone berbasis android. Status keamanan sepeda motor di smartphone adalah sebagai berikut:

1. Jika nilai sensor HC-SR501 = 0 pembacaan sensor HC-SR501 maka status keamanan aman.

2. Jika nilai sensor HC-SR501 = 1 pembacaan sensor HC-SR501 maka status keamanan bahaya.

3. Jika nilai sensor HC-SR04>20 pembacaan sensor HC-SR04 maka status keamanan aman.

4. Jika nilai sensor HC-SR501 <= 20 pembacaan sensor HC-SR501 maka status keamanan bahaya.
5. Jika nilai sensor ACS712 < =3 pembacaan sensor HC-SR501 maka status keamanan aman

6. Jika nilai sensor ACS712 > 3 pembacaan sensor HC-SR501 maka status keamanan bahaya.

Tabel 1 Pin-pin I/O Arduino Uno R3

\begin{tabular}{cll}
\hline \hline No & $\begin{array}{l}\text { Nama Perangkat } \\
\text { Keras }\end{array}$ & $\begin{array}{l}\text { Pin pada Arduino Uno } \\
\text { R3 }\end{array}$ \\
\hline \hline 1 & Sensor SR-HC501 & Digital 10 \\
2 & Sensor HC-SR04 & Digital 8,9 \\
3 & Sensor ACS712 & Analog 0 \\
3 & Bluethoot HC-06 & Digital 0 \& 1 (RX \& TX) \\
4 & Buzzer & Digital 6 \\
\hline \hline
\end{tabular}

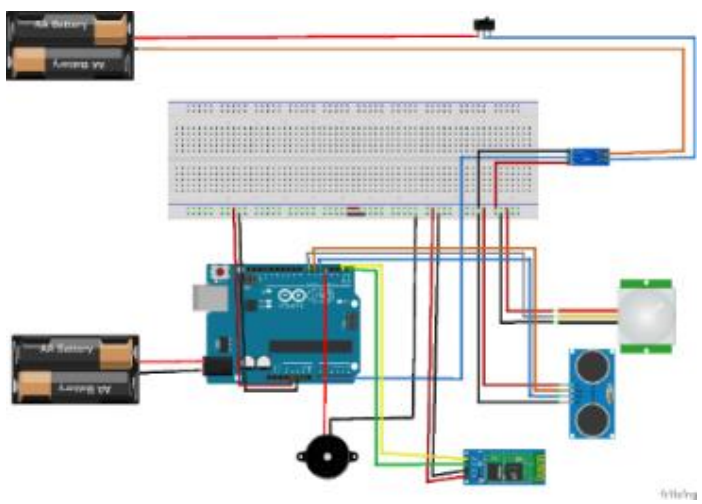

Gambar 5. Rangkaian sistem keamanan

\section{III.2 Perangkat Lunak pada Smartphone}

Android Perancangan dan Pembuatan perangkat lunak pada smartphone android ini menggunakan metode pengembangan Rational Unified Prosess (RUP). Aplikasi android yang dibuat adalah "Motorcycle Security" RUP terdiri dari 4 fase yaitu inception, face elaboration, fase construction dan fase transition.

Harun Sujadi, Pafsi Paisal 


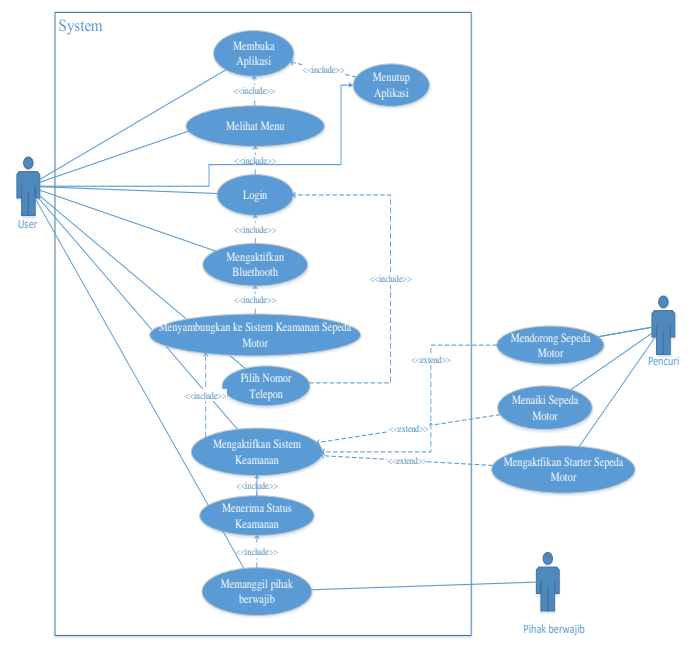

Gambar 6. Use Case Diagram sistem keamanan sepeda motor

Pada fase ini akan berisi tentang tampilan aplikasi motorcycle security yang sudah dirancang pada fase sebelumnya yaitu berupa beberapa screen shoot aplikasi dan pada tahap ini juga aka dibahas mengenai pengujian aplikasi tersebut. Pengujian akan dibahas di bab selanjutnya. Tampilan aplikasi motorcycle security sesuai dengan rancangan sebelumnya sudah dibuat akan dibahas pada bagian ini.

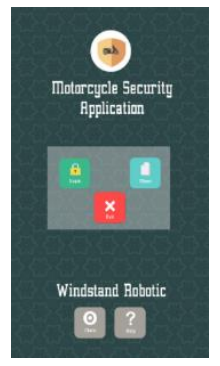

Gambar 7. Tampilan Menu Awal

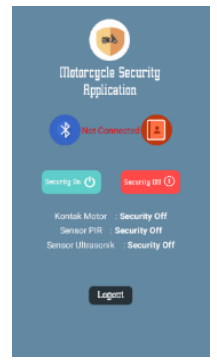

Gambar 8. Tampilan Menu Utama

\section{KESIMPUlan DAN SARAN}

\section{IV.1 Kesimpulan}

Berdasarkan hasil pengujian prototipe yang telah dirancang dan dibangun, maka kesimpulan penelitian dengan judul "Prototipe Sistem Keamanan Sepeda Motor Menggunakan Mikrokontroller Arduino Uno R3 Dengan Sensor HC-SR501 dan HC-SR04" yaitu sebagai berikut :

1. Prototipe sistem keamanan sepeda motor menggunakan perangkat keras mikrokontroller Arduino Uno R3, Sensor HC-SR501, HCSR04, sensor ACS712, bluethooth, buzzer, dll. Dan perangkat lunak yaitu perangkat lunak pada arduino dan aplikasi motorcycle security, dengan metode pengembangan sistem RUP.

2. Untuk mengintegrasikan perangkat keras dengan perangkat lunak pada Prototipe Sistem Keamanan Sepeda Motor Menggunakan Mikrokontroller Arduino Uno R3 Dengan Sensor HC-SR501 dan HC-SR04 ini menggunakan media transmisi bluethooth $\mathrm{HC}$ 06 melalui fungsi pin RX TX yang terpasang pada mikrokontroller, sehingga perangkat keras dan perangkat lunak pada sistem tersebut menjadi terintegrasi.

\section{IV.2 Saran}

Pada prototipe sistem keamanan sepeda motor menggunakan mikrokontroller Arduino Uno R3 Dengan Sensor HC-SR501 dan HC-SR04 masih terdapat kekurangan yang harus dikembangkan untuk meningkatkan kualitas dan nilai fungsionalitasnya karena sistem yang telah dibangun masih berupa model (prototipe).

Adapun beberapa saran untuk pengembangan yang lebih baik yaitu :

1. Perlunya sumber tegangan bukan dari accu, tapi sumber lain yang bisa menyimpan tegangan dan mengalirkannya kembali, karena ditakutkan ketika sumber tegangan dari accu pencuri bisa memotong kabel tegangannya;

2. Penggunaan mikrokontroler yang lebih handal untuk meningkatkan kompleksitas sistem;

3. Menggunakan modul GSM untuk melakukan pengiriman SMS Gateway; agar pemilik sepeda motor yang tidak mempunyai 
smartphone bias menggunakan sistem keamanan tersebut;

4. Pengembangan dengan menggunakan konsep Internet of Thing (IoT) sehingga dapat diakses via internet sehingga pengguna mampu memonitoring sistem keamanan sepeda motor dari jarak jauh;

\section{REFERENSI}

Artanto. 2012. Aplikasi Mikrokontroller Atmega8535 dan Atmega16. Yogyakarta: ANDI.

Badan Pusat Statistik.Data Kriminal 2016. Badan Pusat Statistik, Jakarta-Indonesia.

Mulyanto, Agus. 2009. Sistem Informasi Konsep \& Aplikasi. Yogyakarta: Pustaka Pelajar.

Nazruddin Safaat. 2012 (edisi revisi). Pemrograman Aplikasi Mobile Smartphone dan Tablet PC Berbasis Android. Informatika. Bandung. 